\title{
DOES CHINA NEED TO ABOLISH FAMILY PLANNING POLICY? - ANALYSIS OF FAMILY PLANNING POLICY AND TWO-CHILD \\ POLICY
}

\author{
Yuanyuan Zhou \\ Jinan University, P.R.China and Wuhan University, P.R.China \\ Yumin Lin \\ Jinan University, P.R.China and Wuhan University P.R.China
}

\begin{abstract}
Family-planning policy in China has been implemented for more than 40 years. It has reliably reduced the size of the population, but inevitably it also brought a serious problem of population aging. In 2015, China introduced a new fertility policy “Two-child policy”, which means each couple can have two children. Will the policy fully cope with the aging of population? What detraction effect does it have? Does China need to fully liberate the fertility policy? The article will try to answer these questions.
\end{abstract}

Keywords: Fertility policy, Total fertility rate, Demographic bonus

JEL code: J13, J24

Family planning policy is a population policy to directly control the population. Implemented for nearly 40 years, the policy has effectively controlled the population and improved the quality of the population. It is a key policy to promote China's path of sustainable development and achieve the strategic goal of modernization. Under the condition of steady economic growth rate, the lower the population growth rate, the higher the level of per capita income growth. Accordingly, the extent of the improvement of people's welfare level will be greater, sustainable economic development will be more possible.

\section{Introduction: The Contribution of Family Planning Policy to the Reduction of Population Size in China}

The purpose of population policy is to introduce the scale, structure and distribution of population. Objectively speaking, the implementation of family planning policy to effectively 
control population is in the last resort. In a specific historical stage, the policy was implemented mainly by administrative means, with low capital investment, high political costs and lost of childbearing age women's physical and mental health. Family planning policy creates a demographic bonus period of nearly forty years, during which China has low population support rate, high social savings rate and young working age population. In the year of 2005, a NPC Standing Committee official pointed out on "Forum on Population and Development in the Northwest Area”: Since the implementation of family planning policy in 70s of 20th century, the total fertility rate has fallen to around 1.8. Compared with other countries and regions with the same level of economic development, China's total fertility rate is 1.2 to 1.3 lower. This change kept 300 million people from being born. $<$ National Population Development Strategy Research Report > issued by National Population and Family Planning Commission in January 11, 2006 indicated that Family planning has realized the historical transformation of population reproduction type, from "high birth, low mortality, high growth" to "low birth, low mortality, low growth”. Total fertility rate fell from 5.8 in early 1970s to the current level of 1.8, which below replacement level. More than 400 million people being kept from born, "six billion world population day” delayed for 4 years.

Results of the sixth census of population in 2010 shows that China has increased by 73 million 900 thousand people in 10 years compared with the fifth national census in 2000, growth rate of $5.84 \%$, the average annual growth of $0.57 \%$. The average annual growth rate was $1.07 \%$ from year 1990 to 2000. Fertility decline led to a decline in population dependency ratio of $1 / 3$, creating 40 years of demographic dividend period for economic development.

\section{Policy and Population Status: Economic Structure of "Not rich first old"}

$<$ World population report > released by UN Population Fund in 2005 shows that each woman gave birth to an average of 2.6 children around the whole world in 2005, developed countries 1.5 children while developing countries 2.8 children. China's total fertility rate (1.3) in 2005 was only about half of the average level in the world. It's lower than half of the average level in developing countries and lower than the average level in developed countries. According to < China Statistical Yearbook 2016> published by National Statistics Bureau, total fertility rate of Chinese women in childbearing age is only 1.047, lower than half of the population replacement level (2.1).

Formula for birth rate calculating the age at $\mathrm{Z}$ years:

$$
\begin{aligned}
& f_{x}^{z}=\frac{B_{x}^{z}}{F_{x}(z)} \\
& B_{\mathrm{x}}^{\mathrm{z}}-\mathrm{Z} \text { years } \\
& \text { number of female new born infants at the age of } x \\
& F_{x}(z)-Z \text { years }
\end{aligned}
$$


number of female population at the age of $\mathrm{x}$

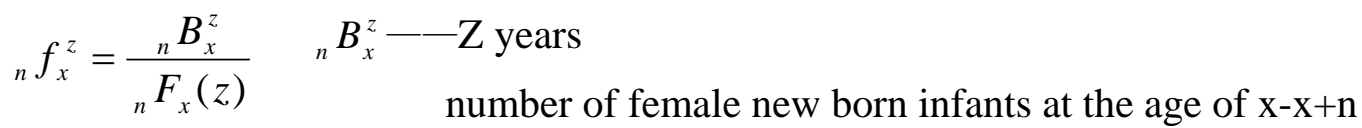

$$
\begin{aligned}
& { }_{n} F_{x}(z)-Z \text { years } \\
& \text { number of female population at the age of } x-x+n
\end{aligned}
$$

Formula for total fertility rate:

$$
T F R^{z}=\sum_{x=\alpha}^{\beta} f_{x}^{z} \quad \begin{aligned}
& \beta-\text { - Female maximum reproductive age } \\
& \alpha-\text { - Female minimum reproductive age }
\end{aligned}
$$

From another perspective, together with effectively controlling the population, family planning policy gives rise to a unique country in which people become old earlier than rich. Increasing proportion of working age population declined constantly and elderly population proportion increased rapidly. Those are the main features of population change in China in recent decades. Data from National Statistics Bureau in Jan. 2014 shows China has a total population of 1 billion 360 million, $14.9 \%$ of which are over 60 years old and being expected to reach $25 \%$ of the total population in 2030. The trend is irreversible.

Prediction results from the National Aging Office show that China will have an average increase of 5 million 960 thousand elderly population annually from 2005 to 2030. By the year 2030, elderly population will reach 351 million. The results of the research group "Research on the Balance of Urban Pension Income and Expenditure Under the Background of Population Aging” of Liaoning University show if in accordance with the existing policy unchanged, deficit of social pooling pension balance will really highlight after 2016. The deficit will reach the peak during 2035-2040, newly increased 100 billion RMB per year. To cope with the financial pressure of the 2030 population aging peak, strategic reserve funds need to be at least 25000 billion RMB. It is necessary for the government to adjust the family planning policy at the right

\begin{tabular}{|c|c|c|c|c|c|}
\hline & $\begin{array}{l}\text { Aging } \\
\text { marks }\end{array}$ & $\begin{array}{c}\text { Peak elderly } \\
\text { population } \\
\text { (100 } \\
\text { million })\end{array}$ & $\begin{array}{c}\text { Aging level } \\
(\%)\end{array}$ & $\begin{array}{l}\text { Population aged } \\
80 \text { and over } \\
\text { (10 } \\
\text { thounsand) }\end{array}$ & $\begin{array}{c}\text { population aged } 80 \\
\text { and over / total } \\
\text { elderly population } \\
(\%)\end{array}$ \\
\hline First Stage & Rapid & 2.48 & 17.17 & 3067 & 12.37 \\
\hline
\end{tabular}
time to keep the population dependency ratio at a reasonable level.

Table 1 China's Aging Population in 2001-2100 
Table 1, cont.

\begin{tabular}{|c|c|c|c|c|c|}
\hline $2001-2020$ & aging stage & & & & \\
\hline $\begin{array}{c}\text { Second Stage } \\
2021-2050\end{array}$ & $\begin{array}{c}\text { Accelerated } \\
\text { aging stage }\end{array}$ & 4.00 & $>30.00$ & 9448 & 21.78 \\
\hline $\begin{array}{c}\text { Third Stage } \\
2051-2100\end{array}$ & $\begin{array}{c}\text { Severe } \\
\text { aging stage }\end{array}$ & 4.37 & Around 31.00 & - & $25.00 \sim 30.00$ \\
\hline
\end{tabular}

Source: According to the "2010 China Population Aging Trend Forecast Report”.

Economic development has greatly increased the average life expectancy of China. One only child has to take care of their parents and 4 grandparents, causing huge pressures. Therefore, it's historically necessary to adjust family planning policy. China's family planning policy has a significant impact on pension system. The lack of the future labor force will directly lead to the vulnerability of the old-age insurance system, driving the reform of delaying retirement age.

From the figure below, population support rate becomes higher and higher, which directly lead to pension fund payment risk. Policy to delay the retirement age is clearly in order.

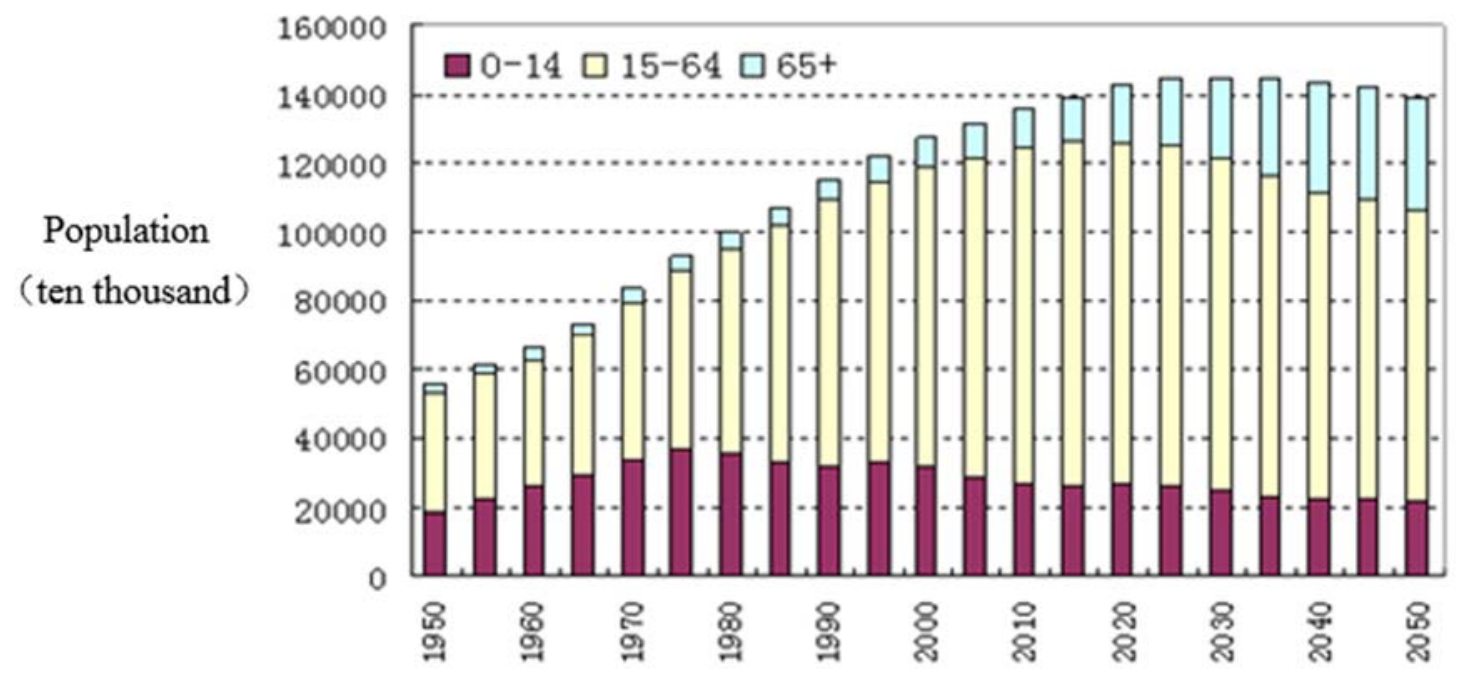

Figure 1. Population Support Rate

Will China have social security fund payment crisis? According to calculation, in future 38 years, cumulative pension gap will reach $75 \%$ of GDP, much higher than the cost of environmental protection. Population structure and pension issues are considered as China's Achilles' Heel.

\section{Research Analysis: Analysis of Single Two-child Policy and Implementation Effect}

Single Two-child policy means that couples would be allowed to have an extra child if only one parent were a singleton and the first child is not a multiple. The policy has been implemented 
throughout the country since 2015. The policy is widely discussed and has very different opinions. Pro. Mu Guangzong from Institute of Gerontology in Peking University thinks that birth interval between two children should be gradually cancelled. (Mu, 2015) Gu Baochang from Center for population and Development Studies in Renmin University said the adjustment of population and fertility policy lags far behind the actual needs, the faster the better.(Gu, 2014) Pro. Zhai zhenwu from School of Sociology and Population in Renmin University thinks it's not mature to universally implement the Single Two-child Policy, with too many risks.(Zhai, 2015)

\section{Effects of single two-child policy on China's population structure}

First, to increase the proportion of young people in our population, to increase the working population. Because of the policy, the total size of the labor force in the next 15 years will be 28 million more annually. And that will greatly alleviate the imbalance between supply and demand of China's future labor force. (Tong Yufen, 2014)

Second, to reduce the degree of population aging, to optimize the population structure of China. China is one of the fastest aging countries in the world. (Wang Peian, 2013) The elderly population will reach a peak of 440 million by the year 2050. The policy is helpful to alleviate the current low birth rate, increase the proportion of young people, reduce the aging of population, improve the age structure of the population. China's population aging will decline to $23.8 \%$ in 2030 because of the policy.

Third, to ease the current situation of the imbalance between men and women in China, to balance the sex ratio at birth. Sex ratio at birth in China is still high with 177.7 in 2012. In a state of natural fertility, to encourage fertility is an effective way to balance the sex of the birth population.

Fourth, to enhance family development ability. Presently, the characteristics of the family in China are gradually showing the characteristics of small family size, the core of the structure, the simplification of the relationship and the mobility of members. A separate two-child policy will help to avoid increasing the sub-mono-children family to alleviate the family structure, enhance the family's ability to support the elderly. The policy also contributes to the healthy development of children and the family's ability to resist risks.

\section{Further Analysis of Supporting System: For The Single Two-child Policy}

In the 2008 Wenchuan earthquake, there were tens of thousands of families who lost their children, including more than 8 thousand families with only one child. Family unit is the basis 
of the national economy, destruction of the family will ultimately undermine the most important part of the economic system. Population policy in China should at least allow two children in one family to achieve population growth. (Coase,1991) In 2008, the fourth national health service survey showed that the prevalence rate of chronic diseases among the people over the age of 65 was about $64.5 \%$, of which the prevalence rate of chronic diseases among the people aged over the age of the city was as high as $85.2 \%$ in China. It's worth worrying about the caring for high proportion of elderly patients with chronic disease in the one-child policy. According to the new sampling data (table below), the average life expectancy of women is higher than that of men, but the prevalence rate of chronic diseases is higher than that of men.

Table 2 The Prevalence of Chronic Diseases in People Over 65 Years Old

\begin{tabular}{|c|c|c|c|}
\hline GENDER & $\begin{array}{c}\text { More than } \\
\text { one disease }\end{array}$ & $\begin{array}{c}\text { More than } \\
\text { one diseases }\end{array}$ & $\begin{array}{c}\text { More than } \\
\text { three diseases }\end{array}$ \\
\hline All & 86.3 & 68.6 & 47.3 \\
\hline Male & 84.3 & 64.1 & 40.7 \\
\hline Female & 88.1 & 72.5 & 53.1 \\
\hline
\end{tabular}

Sample Data: 32042 (Male: 1526 people, Female: 1678 people)

Data sources: Information from the Speech by Geng Qingshan of Guangdong General Hospital on the second session of the Guangdong provincial pension service forum and the Guangdong provincial Pension Service Association Annual Meeting of on the 2016.

China's family size continues to shrink from 1982. The proportion of elderly people living alone is increasing. Family marriage, fertility, pension and other traditional functions are weakened, the ability to resist risks decreasing. China has released the traditional family policy, which is necessary and helpful. The adjustment of fertility policy has a greater impact on women than that on men. Therefore, supporting policies are needed.

First, supporting female employment. The single two-child policy will has a great influence on women's employment. To support female employment, Chinese government should attach great importance on female employment, who give birth to a second child. To avoid the impact of employment on women's choice of fertility.

Second, to ensure the stability of women's jobs. Some women do not dare to have children because they worry about losing their original ideal job after maternity leave. The government should act legislation to protect the work of women before birth.

Third, increasing women welfare. Fertility is not only individual behavior, but also social 
behavior. The government should improve the old-age insurance to assure the policy does not fall through.

\section{Conclusions}

Domestic scholars in China have made a calculation on fertility policy and they have got some conclusions: (1). If the policy implemented in the whole country, the number of births per year will increase by about 1 million. However, the possibility to exceed 2 million people is small. China's total population will peak in 2026 2029. The mean value of the peak population is 1 billion 401 million, while the upper limit is about 1 billion 412 million. (Wang, Zhang, 2014) (2) If the current fertility policy remains unchanged and the fertility level will remain basically stable, China's total population will peak in $2023 \sim 2025$. The mean value of the peak population is 1 billion 392 million, while the upper limit is about 1 billion 410 million.

Single two-child policy has a positive significance on realizing the balance of population scale and structure. With the evolution of time and national conditions, the positive effects will gradually weaken, and the negative effects will begin to appear.

1. Policy is not sufficient to fully improve the age structure and increase the number of labor. To promote the long-term balanced development of the population, the positive impact of the single two-child policy is very obvious, but relatively limited. It must be clearly seen that except for effectively release some of the reproductive potential, the single two-child policy can do more in slow down the trend of aging and improving labor supply and demand pattern. This policy is only a partial adjustment and phased improvement to prevent birth population from sudden change and avoiding the sudden increase in resource and environmental pressures. The implementation of the basic principles is a smooth and orderly, gradual and controllable, reasonable and prudent. We have to continue improving the adjustment of fertility policy rather than come to a standstill.

2. The policy overall considerate about the contribution rate of the population in the implementation of family planning policy and the feasibility of policy adjustment and perfection, ensuring the orderly linkage with the original birth policy. China being vast in territory, there are significant differences in fertility. Some areas already have the full liberalization of the two-child population conditions, while some areas do not have the need to control fertility. Therefore, the full liberalization of two-child should not set a timetable for reunification of the country. According to the evaluation of the effect of the implementation of the single two-child policy, a number of highly developed areas and some mature areas are 
given priority to the full liberalization of the two-child policy at the provincial level. Or the policy can be released in older age groups, to form the situation of adjusting the birth policy step by step nationwide. Reduce the pressure on public services brought by the full liberalization of the two-child policy.

3. Full liberalization of two-child policy will achieve long-term balanced development of the population to create better conditions and is the only way to adjust and improve fertility policy. It has a very significant impact on the level of fertility, population, labor force, the trend of aging and so on.

Assuming that we implement the gradual liberalization of the two-child policy 5 years after the start of the single two-child policy, the peak of the total fertility rate in our country will break the replacement level according to the results of population prediction. The total fertility rate will fall below the replacement level until the birth of the basic energy release is completed. Within several years, it will be better for achieving long-term balanced development of the population if fertility levels are maintained at $1.7 \sim 1.8$, below but close to replacement level. Affected by changes in fertility levels, the number of births will be correspondingly high. But its peak will not exceed 21 million people, and then will quickly fall. China's total population after the implementation of the policy will not exceed 1 billion 460 million people, population growth and zero growth in negative growth will occur around 2030. It can be seen that China can achieve relatively controllable population increment, the total population being relatively stable, which is the basis for ensuring the balance of population size.

\section{Acknowledgment}

This work was supported by Major project of Key Humanities and Social Sciences Base, Ministry of Education of the People's Republic of China $<$ Research on social security fund and solvency management >, Project Number: 16JJD840011.

\section{References}

Wang, G. Z. \& Zhang L. P. (2012) How Many Births Can We Have? Estimation of Potential Policy Fertility. Socio-logical Studies, pp.119-140.

Cao Y. Z. \& Ma J. (2012) The Proportion of Pension Shortfall Will Reach GDP of Up to 75\% 
In The Next 38 Years. Xi'an Evening News. [12 June 2012].

Wang, G. Z. (2011) Preliminary Study on the Effect of Changing the One-child Policy on the Birth Population Size of Beijing. Social Science of Beijing, pp.48-52.

Wu, X. W. (2010) The Effects of First Marriage and First Birth on Second Birth Interval for Chinese Women at Childbear-ing Age: A Study Using Split Population Survival Model. Chinese Journal of Population Science, pp.36-45.

Lin, W. \& Chen, Y. (2006) China Will Usher in the Peak of Population Aging in 2030. China Youth News. [29 September 2006].

Qiao, X. C. \& Ren, Q. (2006) The Choices of Chinese Fertility Policy in the Future. Market \& Demographic Analysis, pp.1-13, 66.

Guo Z. G. (2004) Methodological Discussions on the Population Simulations for Adjustment of Fertility Policy. Chinese Journal of Population Science, pp.2-12. 